\title{
Effect of strenuous maternal exercise before and during pregnancy on rat progeny renal function
}

A.O. Oliveira,

C. Fileto and M.S. Melis
Departamento de Biologia, Faculdade de Filosofia Ciências e Letras de Ribeirão Preto, Universidade de São Paulo,

Ribeirão Preto, SP, Brasil

\section{Correspondence}

M.S. Melis

Laboratório de Fisiologia

Departamento de Biologia

FFCLRP, USP

Av. Bandeirantes, 3900

14040-901 Ribeirão Preto, SP Brasil

E-mail: msmelis@ffclrp.usp.br

C. Fileto is the recipient of a CNPq fellowship (No. 522151-94.9).

Publication supported by FAPESP. .....................

Received December 2, 2002 Accepted December 1, 2003

\begin{abstract}
The effects of strenuous exercise before and during pregnancy on the renal function and morphological alterations of the progeny were determined in a study on female Wistar rats. This research was done based on a previous study carried out in our laboratory, which showed morphological alterations in rats submitted to this kind of exercise. As the form is related to the function, the physiological relevance of submitting a pregnant female to a high-intensity exercise training regimen could be explained by the fact that morphological alterations can influence kidney function. The animals were assigned to one of two groups: control animals that did not exercise during pregnancy and trained animals that swam for 120 min 5 days a week for 8 weeks before pregnancy and daily for $60 \mathrm{~min}$ over a period of 8 weeks starting on the second day of pregnancy. Seven rats of each group were analyzed for morphological alterations and for renal function. The progeny of the rats used for morphological evaluation were born by cesarean section and the progeny of the animals used to evaluate renal function were born normally. The progeny were two months old when renal function was evaluated. Fertility and morbidity were the same for both groups. Strenuous maternal exercise had no significant influence on glomerular filtration rate (GFR) but renal plasma flow was lower in the progeny of the trained group (mean $\pm \mathrm{SD}, 16.65 \pm 3.77 \mathrm{ml} \mathrm{min}^{-1}$ $\mathrm{kg}^{-1}$ ) compared to the progeny of the control group (33.42 $\pm 2.56 \mathrm{ml}$ $\left.\mathrm{min}^{-1} \mathrm{~kg}^{-1}\right)$. Antidiuretic and antinatriuretic effects on the progeny of the trained group were observed, since urine flow as percentage of GFR and the fraction of urinary sodium excretion were lower in this group (1.38 \pm 0.10 and $0.60 \pm 0.04 \%$, respectively) compared to the progeny of the control group $(2.36 \pm 0.11$ and $1.55 \pm 0.20 \%$, respectively). Moreover, in this exercise program, fetuses from trained animals were small-sized $(2.45 \pm 0.19$ vs $4.66 \pm 2.45 \mathrm{~g}$ for control animals) and showed lower differentiation compared to fetuses from the control group. These effects were probably caused by caloric restriction, hypoxia and reduction of umbilical cord length.
\end{abstract}

Key words

- Renal function

- Exercise during pregnancy

- Fetus

- Gestation 
Conflicting results have been reported concerning the effect of endurance exercise before or during pregnancy on fetal development. Studies on rats and mice have indicated that endurance exercise during pregnancy causes a decrease in fetal size $(1,2)$. However, other investigators did not find a correlation between maternal endurance exercise and fetal birth weight (3). Recent studies have shown that moderate physical exercise practiced before and during pregnancy by rats (4) and by women (5) did not affect fetal development, while strenuous antenatal exercise caused reduced birth weight, umbilical cord length and placental weight (1). These conflicting results about the effects of maternal exercise on the fetus are probably due to the different exercise intensities to which the mothers were submitted, to animal familiarity with the physical exercise or to different species of animals used (6).

Little information is available about the modifications of renal parameters induced by physical exercise in the progeny, but renal function during exercise has been studied extensively in man and animals. Pioneering experiments carried out on humans by Wesson Jr. (7) and later by Castenfors (8) showed that physical exercise reduces renal blood flow and glomerular filtration rate (GFR). A decrease in urinary flow and in renal sodium excretion was also observed, probably caused by a higher antidiuretic hormone and aldosterone release during exercise (8). These results were later confirmed in humans and rats (9) and in horses (10).

Renal responses to physical exercise are related to exercise intensity. At low exercise intensity, urinary flow and sodium excretion tend to increase while at high exercise intensity both parameters are decreased considerably (11). Similar results were observed in a study of different renal responses to exercise in humans that ran various distances (12). Thus, the kidney, whose primary function is to regulate the volume and the extracellular liquid composition, can suffer changes in hemodynamics and in sodium and water excretion during exercise, and the magnitude of these alterations is related to exercise intensity.

The effects of endurance exercise training before and during pregnancy on the renal function of the progeny have not been fully clarified. Considering the importance recently attributed to physical activities, including those practiced by pregnant women in physical exercise programs, the purpose of the present study was to investigate the effects of forced training of female rats before and during pregnancy on a) morphological alterations of the fetus, placenta and umbilical cord, and b) renal function of progeny (renal plasma flow, GFR, urine flow, and urinary sodium excretion).

The study was conducted on female Wistar rats weighing 110 to $130 \mathrm{~g}$. The animals were fed a standard pellet diet (Purina Nutrimentos Ltda., Campinas, SP, Brazil) and had free access to water until the morning of the first day of forced swimming.

Two groups of seven females each were submitted to swimming sessions and another two groups of seven females representing the control group were not. One group was used to evaluate morphological alterations of the progeny while the other group was used to evaluate the renal function of the progeny. Before mating, the animals submitted to exercise swam 120 min 5 days a week for 8 weeks. The swimming sessions were always held at the same time of day (in the afternoon) and at water temperatures ranging from $27^{\circ}$ to $30^{\circ} \mathrm{C}$. After mating, the exercise was performed daily for $60 \mathrm{~min}$ starting on the second day of pregnancy. On pregnancy day 21, seven animals of each group were sacrificed for subsequent analysis of the fetus and for the determination of placental weight and umbilical cord length. The other group of animals was left in their cages until the birth of the pups, which were then kept in the cages until they reached a weight 
of $130 \mathrm{~g}$, when renal function was analyzed. The animals that were not exercised received the same treatment as the trained ones, except for the swimming sessions.

Rats born to mothers submitted or not to exercise were anesthetized with sodium pentobarbital $(30 \mathrm{mg} / \mathrm{kg})$, placed on a temperature-regulated table and submitted to tracheotomy. Their body temperature was $37^{\circ}$ to $37.5^{\circ} \mathrm{C}$. The carotid artery was catheterized for blood collection and polyethylene catheters were also inserted into the jugular vein for infusion of Ringer solution. The bladder was catheterized through an abdominal incision for urine collection.

Isotonic Ringer solution containing 10\% inulin and 2\% p-aminohippuric acid (PAH) was infused $i v$ at the rate of $0.03 \mathrm{ml} / \mathrm{min}$ throughout the course of the experiment. After infusion was started, the animals were allowed to equilibrate for 40 to $60 \mathrm{~min}$, and urine was then collected from the bladder at 30 -min intervals. Blood was withdrawn at the midpoint of each clearance period.

Clearance studies were performed on two groups of animals: 1) control progeny, born to mothers which did not exercise, and 2) trained progeny, born to mothers that had exercised. The group of exercised mothers swam 5 days a week for 8 weeks, for $120 \mathrm{~min}$ before and 60 min during pregnancy. Each group contained seven animals.

Inulin concentrations in plasma and urine were determined by the anthrone method (13). Plasma and urinary PAH concentrations were measured by the method of Smith et al. (14). Sodium and potassium concentration in urine and plasma were determined with a Klina flame photometer (Beckman Instruments, Fullerton, CA, USA).

The Student $t$-test was used for statistical analysis of the data, and the results are reported as the mean $\pm \mathrm{SD}$, with the critical level of significance set at $\mathrm{P}<0.05$.

The final body weights of animals of the control and trained groups were 234.60 and 219.00 g, respectively (Table 1). A signifi- cant difference was found only during week 8 of training. Animals of the control group gained approximately $17.9 \mathrm{~g}$ more weight than those of the trained group.

Mean fetal body weight (on pregnancy day 21) was $4.66 \mathrm{~g}$ for the control group and $2.45 \mathrm{~g}$ for the trained group $(\mathrm{P}<0.01$; Figure 1).

Mean placental and umbilical cord weights were significantly higher in fetuses of the control group compared to those of the trained group $(\mathrm{P}<0.01$; Table 1$)$. The mean length of the umbilical cord of the fetuses of the trained group was shorter compared to the control group $(\mathrm{P}<0.01)$. Kidney weight was similar for the animals of both groups.

Endurance exercise did not affect the GFR of the progeny, which was the same for both groups, but a significant decrease in urinary flow was observed for the trained group (Table 1). Renal plasma flow decreased and filtration fraction increased in the trained group. Fractional sodium excretion decreased, suggesting a potential antinatriuretic effect of endurance exercise on the progeny, and the plasma sodium concentration was similar for the control and trained groups (Table 1).

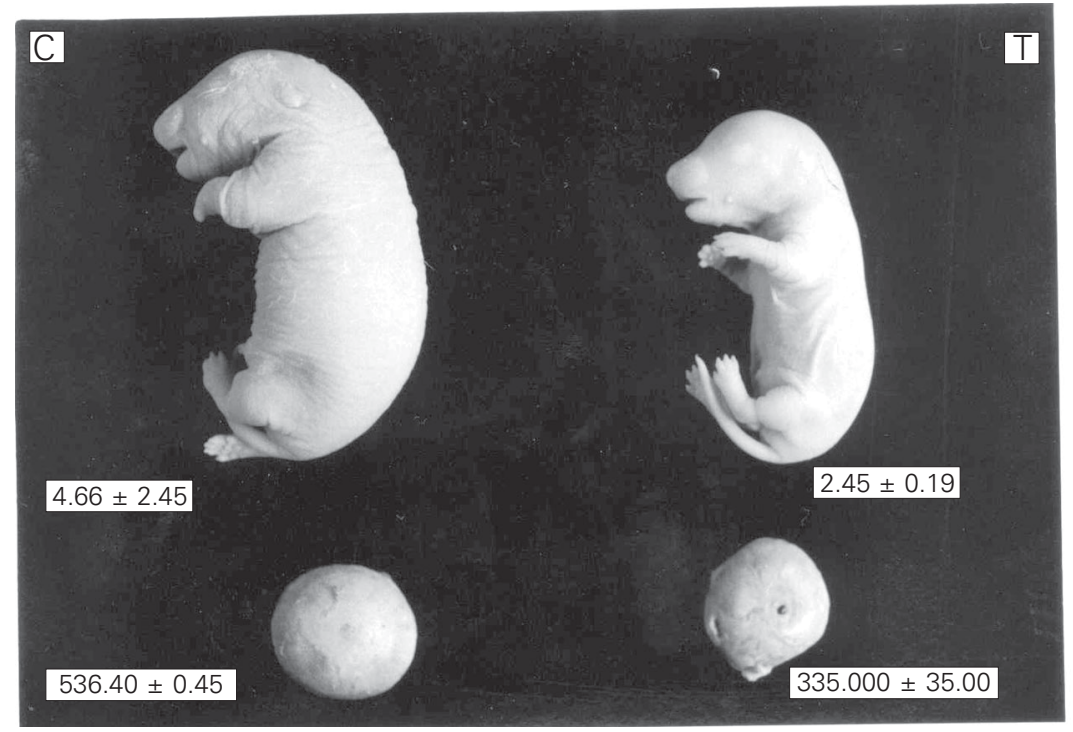

Figure 1. Pups born to mothers of the control $(\mathrm{C})$ and trained $(\mathrm{T})$ groups. Fetal $(\mathrm{g})$ and placental (mg) weights are reported as means \pm SD for 7 pups in each group. 
The mean body weight of trained fetuses was lower than that of control fetuses. Fetal growth seems to be influenced by maternal activity, as shown in some investigations which reported significantly larger babies born to moderately trained women compared to non-trained or heavily trained women (2). In the latter group, the reduction could be explained by a lower neonatal fat mass. Therefore, it has been suggested that intense maternal exercise may compromise fetal development $(1,4,5,15)$.

In our experiments, the placental weight of rats submitted to exercise was lower than the controls, in agreement with some studies (4) that showed a decrease of placental weight parallel to the decrease of fetal body weight. A smaller placenta probably has a lower blood flow, resulting in significant fetal hypoxia that may lead to retarded intrauterine growth (4). On the other hand, moderate maternal exercise enhances fetal and placental growth (3).

In the present study, the umbilical cords of fetuses whose mothers were submitted to endurance exercise were shorter, indicating limitation of fetal movement (1).

It is important to emphasize that there

Table 1. Effect of strenuous maternal exercise before and during pregnancy on rat progeny renal function.

\begin{tabular}{|c|c|c|}
\hline Maternal and offspring parameters & Control & Trained \\
\hline Final body weight (g) & $234.60 \pm 7.80$ & $219.00 \pm 5.95^{*}$ \\
\hline Umbilical cord weight (mg) & $19.52 \pm 3.23$ & $13.80 \pm 2.00^{*}$ \\
\hline Umbilical cord length $(\mathrm{cm})$ & $2.44 \pm 0.10$ & $1.56 \pm 0.12 *$ \\
\hline Progeny kidney weight (g) & $3.40 \pm 0.08$ & $3.30 \pm 0.11$ \\
\hline Progeny relative kidney & $0.014 \pm 0.06$ & $0.015 \pm 0.09$ \\
\hline Progeny $\mathrm{P} \mathrm{Na}+(\mathrm{mEq} / \mathrm{l})$ & $140.00 \pm 1.66$ & $138.57 \pm 0.90$ \\
\hline Progeny GRF (ml min-1 $\left.\mathrm{kg}^{-1}\right)$ & $6.29 \pm 0.71$ & $6.31 \pm 0.11$ \\
\hline Progeny V/GRF (\%) & $2.36 \pm 0.11$ & $1.38 \pm 0.10^{*}$ \\
\hline Progeny RPF (ml min-1 $\left.\mathrm{kg}^{-1}\right)$ & $33.42 \pm 2.56$ & $16.65 \pm 3.77^{*}$ \\
\hline Progeny FF (\%) & $0.19 \pm 0.01$ & $0.44 \pm 0.05^{*}$ \\
\hline Progeny $\mathrm{FeNa}^{+}(\%)$ & $1.55 \pm 0.20$ & $0.60 \pm 0.04^{*}$ \\
\hline
\end{tabular}

Data are reported as means \pm SD for 7 animals per group. $\mathrm{FeNa}^{+}=$fraction of urinary sodium excretion; $F F=$ filtration fraction; $\mathrm{GRF}=$ glomerular filtration rate; $\mathrm{P} \mathrm{Na}{ }^{+}=$ plasma sodium concentration; RPF $=$ renal plasma flow; V/GFR = urine flow as percentage of glomerular filtration rate. ${ }^{*} \mathrm{P}<0.01$ compared to control (Student $t$ test). have been no previous reports of renal function in pups born to mothers who practiced moderate or endurance exercise. Studies on humans using PAH clearance have demonstrated a decrease in renal plasma flow after physical exercise which was related to exercise intensity $(16,17)$. An explanation for this reduced flow could be the intrarenal blood flow distribution, leading to a drop in the rate of renal PAH extraction during exercise (17).

In the present study, we observed a marked decrease in renal plasma flow in the progeny of trained mothers compared to control, which agrees with the results cited above. During exercise, blood flow can be deviated from the renal circulation to active muscle (18), but it has been shown that GFR is maintained constant until exercise intensity is increased $(9,16,19)$. In horses, GFR decreases by about $40 \%$ at any exercise intensity (10); in man, GFR seems to be more resistant to the effects of exercise, but it is hard to compare exercise intensity between such different species. Despite the significant decrease in renal plasma flow induced by strenuous exercise, GFR did not change in our experiments. Probably, the balance of water and salt was maintained in the animal body and/or the modification of the tonus of afferent and efferent arterioles kept the GFR constant.

We also observed a decrease in urinary flow in animals born to mothers that exercised compared to the control mothers, even when this parameter was calculated in terms of GFR percentage. It is commonly found in the literature that increased antidiuretic hormone and aldosterone release due to endurance exercise plays a role in the process of urinary flow reduction observed in animals exercised during pregnancy $(8,9)$. However, no experiments were done concerning this point in the present study. A reduction of sodium excretion in animals whose mothers were submitted to swimming during pregnancy was also observed. The literature 
shows that the decrease of sodium and water excretion during strenuous exercise in spite of an unchanged GFR may be explained by high production of aldosterone and by the deviation of blood from the kidneys to other organs during exercise $(11,17)$. Therefore, the model used in the present study does not discriminate between the direct and indirect effects of endurance training on renal sodium reabsorption.
In summary, in Wistar rats strenuous physical exercise during pregnancy can result in smaller and less differentiated fetuses, effects probably related to caloric restriction, hypoxia and reduction of umbilical cord length. Thus, maternal physical exercise decreases renal plasma flow and has antidiuretic and antinatriuretic effects on the progeny.

\section{References}

1. Ribeiro $C A L$, Maia Campos $G$, Melis MS, Sala MA \& Lopes RA (1991). Alteraciones morfológicas y estereológicas del epitelio lingual de fetos de rata provocadas por el ejercicio materno. Archivos de la Facultad de Medicina de Zaragoza, 30: 84-90.

2. Riemann MK \& Hansen ILK (2000). Effects on the fetus of exercise in pregnancy. Scandinavian Journal of Medicine and Science in Sports, 10: 12-19.

3. Bell R \& Palma S (2000). Antenatal exercise and birthweight. Australian and New Zealand Journal of Obstetrics and Gynaecology, 40: 70-73

4. Houghton PE, Mottola MF, Plust JH \& Schachter CL (2000). Effect of maternal exercise on fetal and placental glycogen storage in the mature rat. Canadian Journal of Applied Physiology, 25: 443-452.

5. Clapp 3rd JF, Kim H, Burciu B, Schmidt S, Petry K \& Lopez B (2002). Continuing regular exercise during pregnancy: Effect of exercise volume on fetoplacental growth. American Journal of Obstetrics and Gynecology, 186: 142-147.

6. Pivarnik JM (1996). Cardiovascular responses to aerobic exercise during pregnancy and postpartum. Seminars in Perinatology, 20: 242-249.

7. Wesson Jr LG (1974). Kidney Function in Exercise. 2nd edn. How \& Harper, New York.

8. Castenfors J (1967). Renal function during exercise. Acta Physiologica Scandinavica, 70: 1-44.

9. Poortmans JR \& Vanderstareten J (1994). Kidney function during exercise in healthy and diseased humans. An update. Sports Medicine, 18: 419-437.

10. Gleadhill A, Marlin D, Harris PA \& Michell AR (2000). Reduction of renal function in exercising horses. Equine Veterinary Journal, 32: 509-514.
11. Shizuru EM, Freud BJ, Hashiru GM \& Clay-Baugh JR (1991). Hormonal, electrolyte, and renal responses to exercise are intensity dependent. Journal of Applied Physiology, 70: 900-906.

12. Poortmans JR (1995). Renal response to exercise in healthy and diseased patients. Nephrologie, 16: 317-324.

13. Fuehr J, Kaczmarzik J \& Kruttgen CD (1955). Eine einfache kolorimetrische Methode zur Inulin Bestimmung für Nierenclearance Untersuchungen bei Stoffwechsel Gesunden und Diabetikern. Klinische Wochenschrift, 33: 729-730.

14. Smith HW, Einkelstein N, Aliminosa L, Crawford B \& Graber M (1945). The renal clearances of substituted hippuric acid derivatives and other aromatic acids in dog and man. Journal of Clinical Investigation, 24: 388-404.

15. Terada M (1974). Effects of physical activity before pregnancy on fetuses of mice exercised forcibly during pregnancy. Teratology, 10: $141-144$

16. Clapp 3rd JF, Kim H, Burciu B \& Lopez B (2000). Beginning regular exercise in early pregnancy: Effect on fetoplacental growth. American Journal of Obstetrics and Gynecology, 183: 1484-1488.

17. Poortmans JR (1990). Postexercise proteinuria in normal and diseased humans. Japanese Journal of Constitutional Medicine, 54: 818.

18. Hammond RL, Augustyniak RA, Rossi NF, Churchill PC, Lapanowski K \& O'Leary DS (2000). Heart failure alters strength and mechanisms of the muscle metaboreflex. American Journal of Physiology, 278: H818-H828.

19. Sanders M, Rasmussen S, Cooper D \& Blood C (1976). Renal and intrarenal flow distribution in swine during severe exercise. Journal of Applied Physiology, 40: 932-935. 